Article

\title{
Temperature-Compensated Force/Pressure Sensor Based on Multi-Walled Carbon Nanotube Epoxy Composites
}

\author{
Nghia Trong Dinh and Olfa Kanoun* \\ Electrical Measurements and Sensor Technology, Technische Universität Chemnitz, \\ Reichenhainer Str. 70, Chemnitz 09126, Germany; E-Mail: dinh_trong_nghia@ hotmail.com \\ * Author to whom correspondence should be addressed; E-Mail: olfa.kanoun @etit.tu-chemnitz.de; \\ Tel.: +49-371-531-369-31; Fax: +49-371-531-836-931.
}

Academic Editor: Vittorio M.N. Passaro

Received: 15 February 2015 / Accepted: 29 April 2015 / Published: 12 May 2015

\begin{abstract}
In this study, we propose a multi-walled carbon nanotube epoxy composite sensor for force and pressure sensing in the range of $50 \mathrm{~N}-2 \mathrm{kN}$. A manufacturing procedure, including material preparation and deposition techniques, is proposed. The electrode dimensions and the layer thickness were optimized by the finite element method. Temperature compensation is realized by four nanocomposites elements, where only two elements are exposed to the measurand. In order to investigate the influence of the filler contents, samples with different compositions were prepared and investigated. Additionally, the specimens are characterized by cyclical and stepped force/pressure loads or at defined temperatures. The results show that the choice of the filler content should meet a compromise between sensitivity, temperature influence and noise behavior. At constant temperature, a force of at least $50 \mathrm{~N}$ can be resolved. The measurement error due to the temperature influence is $150 \mathrm{~N}$ in a temperature range of $-20^{\circ} \mathrm{C}-50^{\circ} \mathrm{C}$.
\end{abstract}

Keywords: carbon nanotubes; multi-walled carbon nanotubes; epoxy; composite; force sensor; pressure sensor; electrical response; thermal response; temperature compensation

\section{Introduction}

The measurement of mechanical quantities, such as force, torque or pressure, is a challenging task in science and engineering. Very often, a deformation element, like a beam, a membrane or an axle [1], 
is needed, so that the force, pressure or torque is transformed to a strain, which can be measured by a strain sensor. For this, metallic or semiconductor strain gauges (SGs) can be used. Due to lower signal noise and higher mechanical stability, metallic SGs are more frequently used than semiconductor SGs. Nevertheless, metallic SGs show a limitation considering their gauge factor in the range of two, which is comparatively low. New promising sensors based on polymer [2], printable metal inks [3], inorganic [4] or organic composites [5] show a higher sensitivity than metallic SGs and provide therefore interesting solutions for many applications. Recently, many researchers reported on flexible electronics [6], flexible strain sensors [7] and pressure sensors [8] by using nanocomposites. Most of them use nanoparticles, such as quantum dot, nanowire, graphene and carbon nanotubes (CNTs). The one-dimensional structure of CNTs and their semiconducting or quasi-metallic properties $[9,10]$ make them suitable for a large field of applications. The performances of a single CNT referring to the electrical transport [11], the thermal transport [12], in electronic applications [13] and also the sensitivity in sensor application, e.g., for strain measurement $[14,15]$ are better than CNT networks. Even though a single CNT has better performance, there are enormous technological challenges for series fabrication. An additional advantage of the CNTs in comparison to other nanomaterials is the high aspect ratio between length and diameter; that is why the electrical percolation threshold of CNTs is three-times lower than carbon black in Zhao's report [16]. Diverse deposition methods can be applied to fabricate a piezoresistive film, such as spraying [17], filtering [18], spin coating [19] dip coating [20], inkjet printing [21] and screen printing techniques [22].

The piezoresistivity of nanomaterials in polydimethylsiloxane (PDMS) for pressure application are investigated in previous reports, e.g., for carbon black [23] and carbon nanotubes [24]. However, the applicable pressure is low (0-0.2 MPa) [24] for elastomer. This measurement range is interesting, for example, on the human periphery [25].

For a higher pressure range, for example, in machines, polymers with a higher elasticity modulus, such as thermoplastic or thermosetting plastic, are necessary. The strain dependency of CNT composites in such materials was investigated for different material compositions. The gauge factor decreases by increasing the CNT filler content [26]. However, Hu et al. show that the electrical signal of low filler content could be unstable (noisy) due to the unstable destruction and construction of conductive paths [5]. Kang et al. show a repeatable electrical signal and fast sensor response time in less than $0.3 \mathrm{~ms}$ for $0.05 \mathrm{wt} \%$ single-walled carbon nanotubes (SWCNTs), which are embedded in polyimide, in a pressure measurement up to $5 \mathrm{MPa}$ [27]. However, the signal quality depending on different filler content was not investigated. Mohiuddin et al. dispersed multi-walled carbon nanotubes (MWCNTs) in polyether ether ketone. In this investigation, the temperature dependence from $20^{\circ} \mathrm{C}$ up to $140{ }^{\circ} \mathrm{C}$ and the pressure dependence up to $40 \mathrm{MPa}$ were studied [28]. However, the electrical responses show a big drift after temperature treatment and pressure loading [29].

In this paper, we investigate the sensing behavior of MWCNT-epoxy composite by applying pressure with different loading profiles. Thereby, not only the high sensitivity is important, also the sensitivity to temperature influence and the signal-to-noise ratio are further important criteria. For these reasons, another focus of this work is the comparison between the pressure sensitivity, the temperature influence and the signal noise of the MWCNT-epoxy composite by varied filler contents. The resistance of a CNT composite is strongly dependent on the temperature [30,31]; this effect reduces the measurement 
accuracy and should be therefore compensated. Hence, we investigate the efficiency of the temperature compensation with a Wheatstone bridge.

\section{Preparation of the Nanocomposite}

The shell quality and the chirality of the CNTs play a major roll in the conductivity of a composite. Another aspect is the load transfer between the polymer matrix and the CNTs. Due to the covalent bonding between functionalized CNTs and the polymer matrix, the elastic modulus with functionalized CNTs is higher than non-functionalized CNTs [32]. However, the functionalization can destroy the CNT shells and reduces the conductivity of the composite [33]. For this reason, non-functionalized MWCNTs are chosen in this study.

The fabrication parameters and the dispersion methods have a big influence to the mechanical and electrical properties [34,35]. A high shear rate can shorten the CNTs and decreases the conductivity [34]. Therefore, the fabrication parameters need to be chosen carefully. Another effect is the rise in viscosity after MWCNTs are added into the epoxy [36]. Too high a viscosity makes the deposition of homogenous and reproducible layers difficult.

\subsection{Characterization of MWCNTs}

The outer shells are the shells mainly responsible for the electron transport in MWCNTs [37,38]. An exchange of electrons between two perfect shells is unusual, because the resistance between the shells should be 10,000-times [39] higher than in one shell. Subsequent investigations point out that defects increase the resistance, but controlled shell defects can reduce the distance between two shells from $0.34 \mathrm{~nm}-0.138 \mathrm{~nm}$ [40] and increase the number of conduction channels. Agrawal et al. demonstrated that a moderate shell defect has even higher conductivity than a MWCNT with less shell defects [41]. The conductivity of a MWCNT depends also on the number of the conduction channels and, consequently, the MWCNT diameter [42]. Therefore, the shell quality and the diameter of the commercially available MWCNTs (purchased from Future Carbon) are investigated by high resolution transmission electron microscopy (HRTEM). Except for few positions, most MWCNTs have continuous shells with an average diameter of $11 \mathrm{~nm}$. The image of one MWCNT is depicted in Figure 1a. The corresponding average shell numbers are eleven (Figure 1b).

\subsection{MWCNT-Epoxy Composite}

In this study, composites with MWCNT filler contents from $1 \mathrm{wt} \%$ up to $2 \mathrm{wt} \%$ are investigated. The whole preparation process of the MWCNT-epoxy composite are depicted in Figure 2. The MWCNTs and the epoxy, namely Rütapox ${ }^{\circledR}$ L20 (purchased from R \& G Faserverbundwerkstoffe GmbH), are pre-dispersed by "Future Carbon" with a filler content of $4 \mathrm{wt} \%$. Afterwards, the dispersion was diluted to the desired concentration. After the dispersion was diluted, the dispersions were mixed with a magnetic stirrer at $100 \mathrm{rpm}$ for $6 \mathrm{~h}$. The samples are immersed in heated silicon oil at $80^{\circ} \mathrm{C}$ to reduce the viscosity during this process. To achieve more homogeneity, the dispersions are subjected to a three-roll mixer from the company EXAKT with the name E80. The MWCNT composite is dispersed three times 
with different gap spacing, while the velocity with $50 \mathrm{rpm}$ remains the same. In the first dispersion step, the gap space between the first and the second rolls (G1) is $50 \mu \mathrm{m}$, and the gap space between the second and the third rolls (G2) is $20 \mu \mathrm{m}$. In the second step, the gap spaces are $20 \mu \mathrm{m}(\mathrm{G} 1)$ and $10 \mu \mathrm{m}(\mathrm{G} 2)$. Finally, in the third step, the gap spaces are $10 \mu \mathrm{m}(\mathrm{G} 1)$ and $5 \mu \mathrm{m}(\mathrm{G} 2)$.
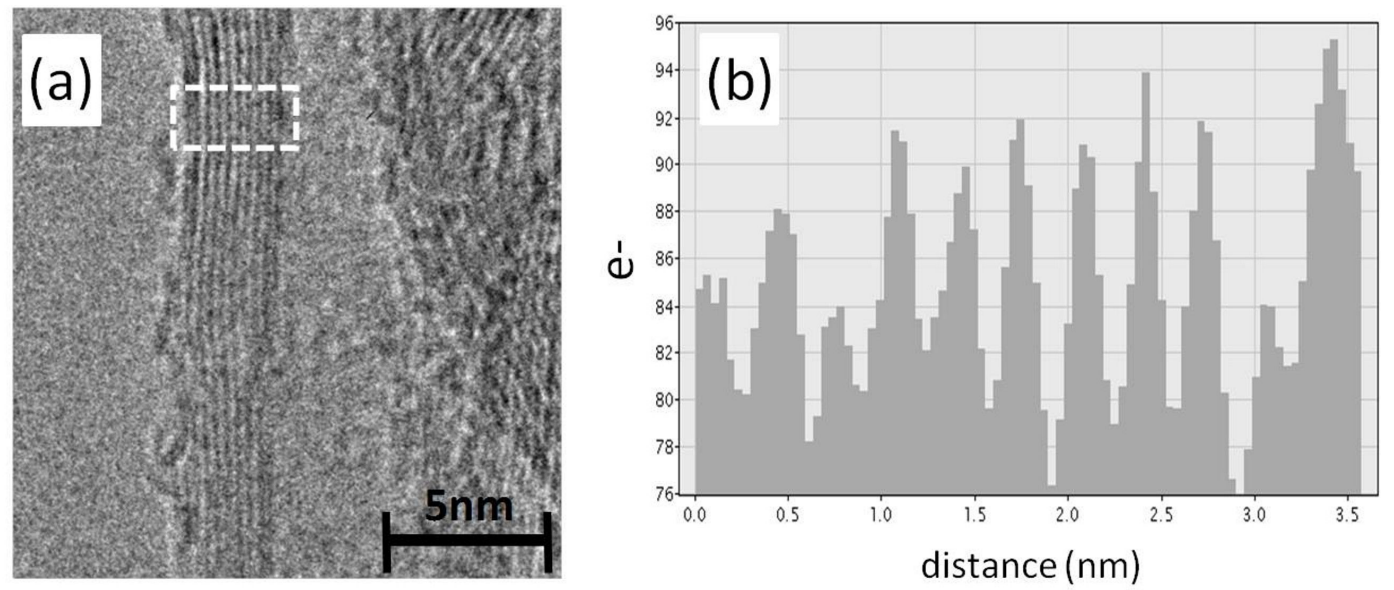

Figure 1. Analysis of MWCNTs by HRTEM; (a) HRTEM image of MWCNT; (b) analysis of the shell numbers.

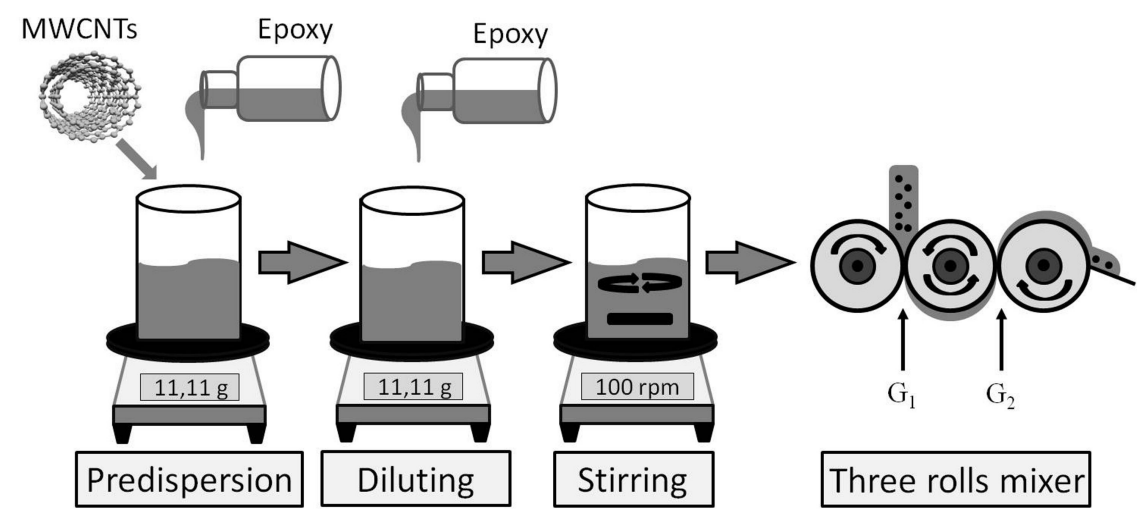

Figure 2. Preparation processes of the MWCNT-epoxy composite.

\section{Device Design and Layer Deposition}

In order to improve the pressure sensitivity, we propose to use a Wheatstone bridge, which is also suitable for reducing the temperature effects. Due to the low conductivity of the composite, an interdigital electrode was chosen. The electrodes of an interdigital structure are parallel interconnected, so that the total resistance is reduced. Additionally, the influences of the electrode dimensions and the layer thickness to the nominal resistance are investigated by the finite element method (FEM).

\subsection{Sensing Structures and Temperature Compensation Concept}

The resistance changes of the realized sensing elements will have the same sign, if they are pressed at the same time. Therefore, we propose to use the middle elements in a full bridge for the force/pressure measurement. This corresponds to a half bridge structure (Figure 3a,c). Elements 1 and 4 are only 
responsible for the balance of the bridge voltage $\left(V_{b r}\right)$. They have the same temperature, like Elements 2 and 3, but are not exposed to the deformation. When a pressure is applied to Elements 2 and 3, the resistance will be reduced $\left(-\Delta R_{2} ;-\Delta R_{3}\right)$. The resistance changes cause potential changes of the voltages; hence, the bridge voltage is unequally zero. In case of a half bridge, the resistance change $\Delta R$ (for $\Delta R=\Delta R_{2}=\Delta R_{3}$ ) can approximately be calculated with following equation, whereby $V_{0}$ is the supply voltage, $V_{b r}$ the bridge voltage and $R_{0}$ is a referent resistance at a defined force.

$$
\Delta R=\frac{V_{b r} \cdot 2 \cdot R_{0}}{V_{0}}
$$

For the temperature compensation, all four elements are exposed to the same temperature (Figure $3 b$ ). If the nominal resistances and temperature coefficients of all four elements are equal, the resistance changes due to temperature have the same sign and value (that means $\Delta R_{1}=\Delta R_{2}=\Delta R_{3}=\Delta R_{4}$ ). In this case, the contribution of temperature change to the bridge voltage is neglectable, so that the temperature influence is compensated.

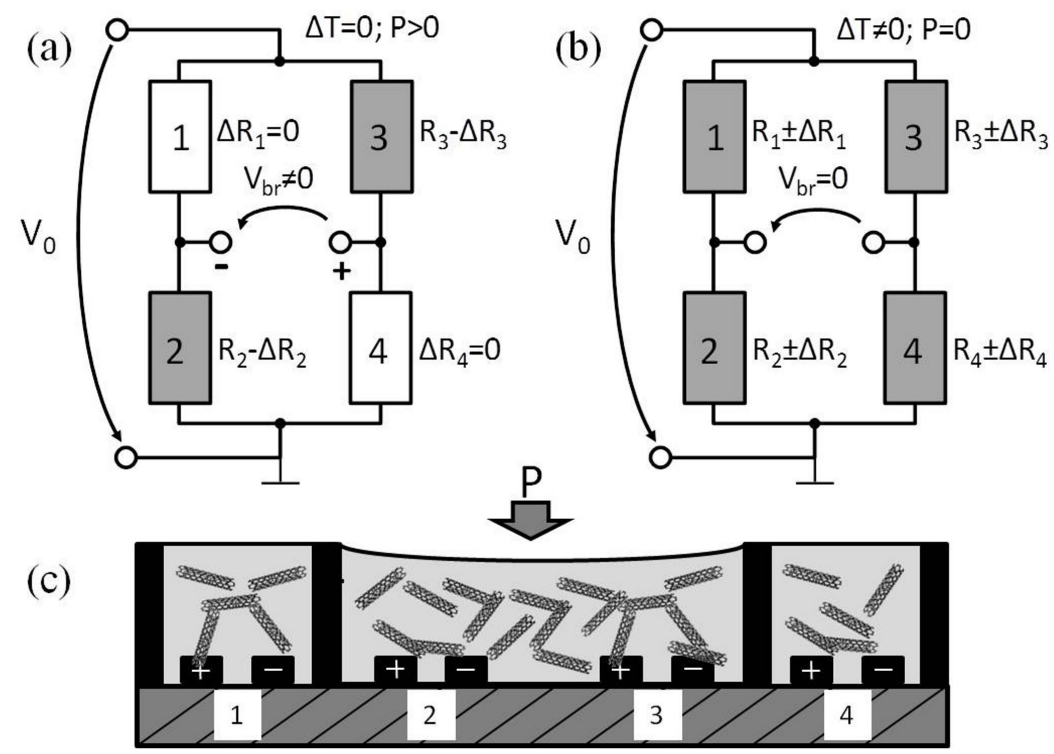

Figure 3. Sensing concept with a half Wheatstone bridge: (a) half bridge circuit for the force/pressure sensing; (b) full bridge circuit for the temperature compensation; (c) four sensing elements on a substrate.

\subsection{Electrode Modeling and Design}

The resistances of the sensing elements depend on the conductivity of the composite, electrode width, electrode distance between two electrodes and the thickness of the layer. Depending on the filler content, shell quality, MWCNT diameter and length, the conductivity of MWCNT composites can be distributed in a big range from $2 \times 10^{-4} \mathrm{~S} / \mathrm{m}$ up to $1 \times 10^{4} \mathrm{~S} / \mathrm{m}$ [43-48]. For this reason, a quantitative resistance calculation is not appropriate, due to the unknown conductivity. For temperature compensation within a Wheatstone bridge, elements should have similar resistance values. If the four resistances have a big variation, the temperature compensation will not be optimal. The resistance values especially depend on the manufacturing tolerances of the electrodes and the layer thickness. That is why we investigate the resistance changes due to the changing of these parameters by FEM in this section, in order to find 
out the suitable electrode dimensions and layer thicknesses. That led to less dependence of the nominal resistance due to the manufacturing tolerances.

The FEM modeling was carried out by using the software, Comsol Multiphysics ${ }^{\circledR}$ (Version 12), with the "AC/DC Module" and the "Electric Currents Interface". The model was simulated in a stationary electrical field, and a reduced 3D model was used to decrease the computing time. As model inputs, the material copper with a conductivity of $5.99 \times 10^{7} \mathrm{~S} / \mathrm{m}$ for the electrodes and a representative conductivity of $1 \mathrm{~S} / \mathrm{m}$ for the MWCNT composite was chosen. As boundary conditions, a current input of $1 \mathrm{~mA}$ on the plus electrodes was defined, and the minus electrodes were grounded. A systematic distribution of the electrical field in the interdigital electrodes is shown in Figure 4a.

By varying the electrode distance $(100 \mu \mathrm{m}-200 \mu \mathrm{m})$ and layer thickness $(100 \mu \mathrm{m}-500 \mu \mathrm{m})$, the resistance of the element was calculated by simulation. The results of the model show that the resistance change is reduced by increasing the layer thickness, and it reaches saturation at a layer thickness of $400 \mu \mathrm{m}$. By decreasing the electrode distance between two electrodes, saturation is already reached for the thinner layer (Figure 4c). In other words, to achieve similar resistance values, the electrode distance should be as small as possible and the layer thickness as thick as possible.
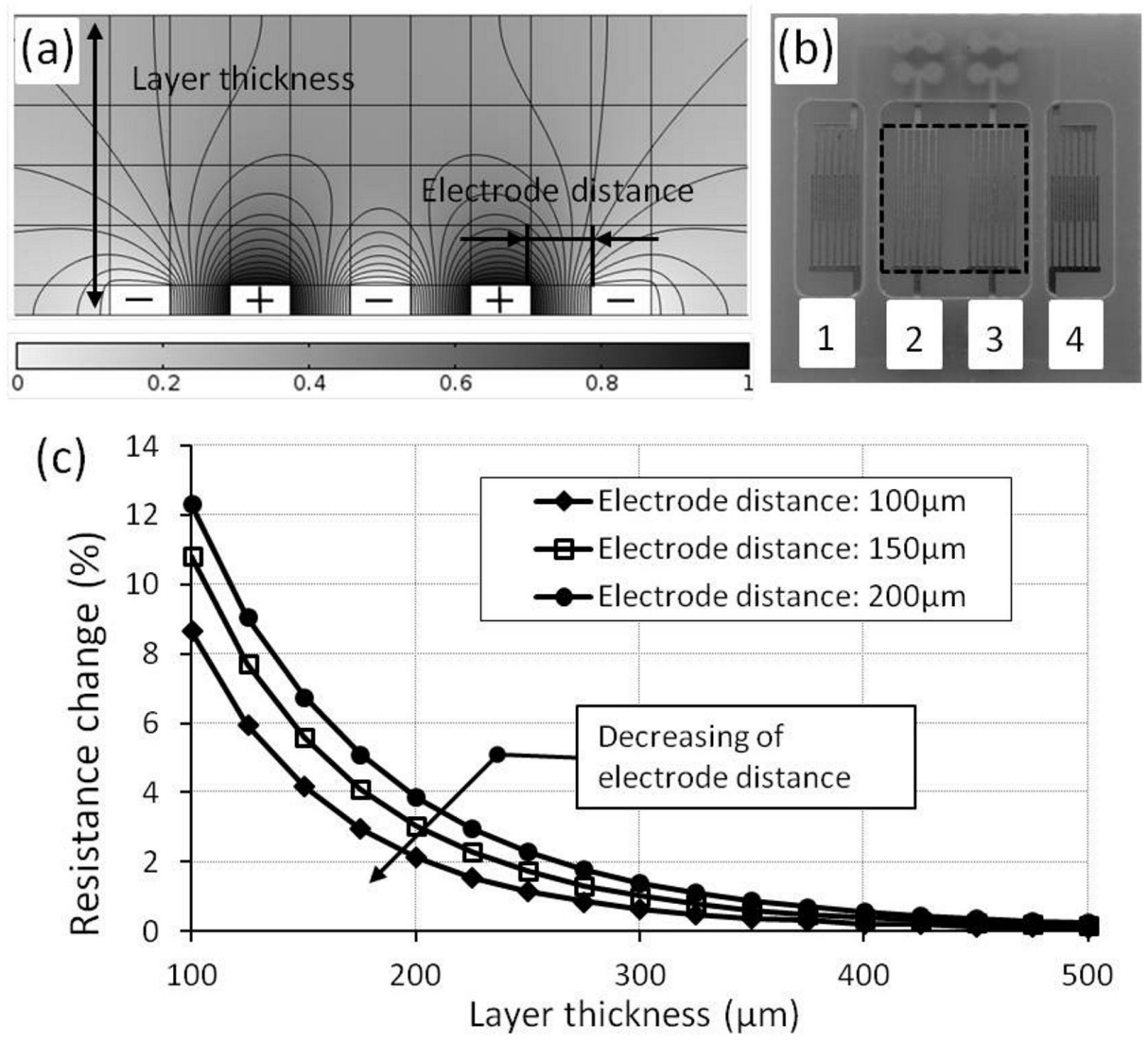

Figure 4. Electrode modeling and design: (a) electrical field distribution between interdigital electrodes; (b) image of fabricated interdigital electrodes on printed circuit board substrate; (c) resistance change depends on the layer thickness and electrode distance.

Depending on the fabrication limit, the optimized dimensions of $150 \mu \mathrm{m}$ for the electrode width and $100 \mu \mathrm{m}$ for the distance between two electrodes were chosen. To get a high reproducibility (variation of less than $1 \%$ ) of the nominal resistance, the layer thickness should be greater than $400 \mu \mathrm{m}$. Based 
on these modeling results, interdigital electrodes with four elements were designed and fabricated on conventional printed circuit board substrate (FR-4) (Figure 4b).

\subsection{Piezo-Sensitive Layer Deposition}

To have reproducible resistance, the layer thickness should be greater than $400 \mu \mathrm{m}$. For such a thickness, screen printing or blade coating are suitable techniques. In this work, blade coating is used, due to the lower demand on the morphology of the dispersion. Before the deposition process, the dispersed composite was mixed with the curing agent, namely epoxy hardener (EPH) 161 (purchased from R \& G Faserverbundwerkstoffe $\mathrm{GmbH}$ ) at a ratio of $4: 1$.

After the blade coating, the composite was dried at room temperature for $24 \mathrm{~h}$. Afterwards, an additional annealing process at $60^{\circ} \mathrm{C}$ for a further $24 \mathrm{~h}$ was applied to achieve the final mechanical strength. The principles of the layer deposition and the fabricated sensing device are depicted in Figure 5.
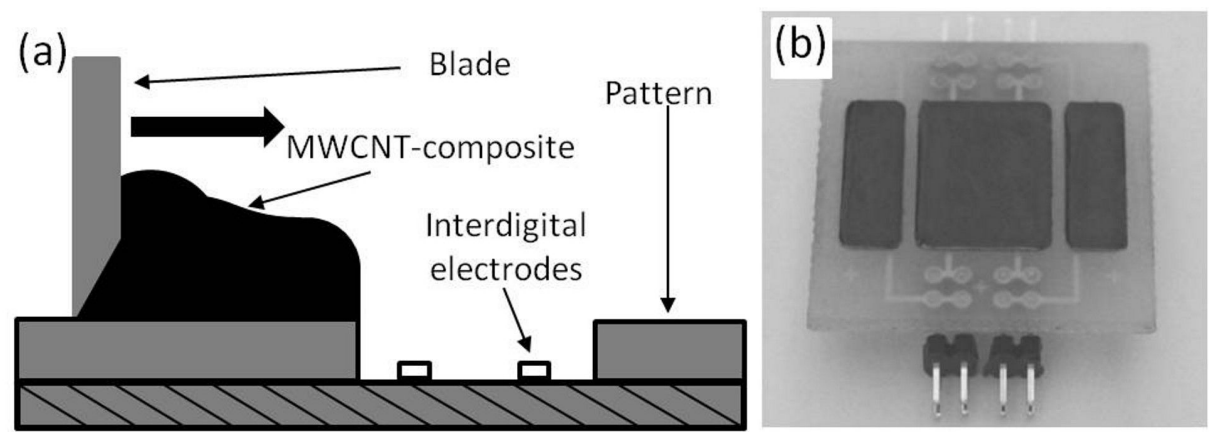

Figure 5. Fabrication of the piezo-sensitive layer: (a) principle of layer deposition by blade coating; (b) image of the fabricated sensing device.

\section{Force/Pressure and Temperature Measurement Setups}

In order to evaluate the reproducibility of the sensing response and the signal-to-noise ratio, the defined pressure load and temperature are needed. Thereby, a synchronization between the excitation signals and response signal is necessary. Additionally, the measurement setups should be able to generate static, cyclical and stepped loads. Furthermore, the sensing elements can be characterized separately (one element) or in a Wheatstone bridge (four elements). Two different measurement setups, namely pressure and temperature measurements, were used in this study. In Figure 6, the scheme of the pressure measurement is pictured.

A source-meter (Keithley 2026) is responsible for the power supply. When one single element is measured, a constant current of $15 \mu \mathrm{A}$ is applied. For the bridge circuit, a supply voltage of $0.2 \mathrm{~V}$ was chosen. The resistance change can be calculated by the measurement of the bridge voltage. Using the data acquisition device (National Instruments 9219), the bridge voltage and the force signal from the universal testing machine are measured. The universal testing machine presses the sensitive area through a stamp of $1 \mathrm{~cm}^{2}$ up to a force of $2 \mathrm{kN}(20 \mathrm{MPa})$. Thereby, a velocity of $0.1 \mathrm{~mm} / \mathrm{min}$ was chosen. All signals are recorded from the program "Labview" for subsequent analysis. The temperature measurement setup has nearly the same configuration. Instead of the universal testing machine, a climate chamber (Vötsch VT 
$4002)$ is used. The samples are measured from $-20^{\circ} \mathrm{C}$ up to $80^{\circ} \mathrm{C}$. To make sure that the samples have the desired temperature, the temperature change is $5^{\circ} \mathrm{C}$ and remains constant for $30 \mathrm{~min}$.

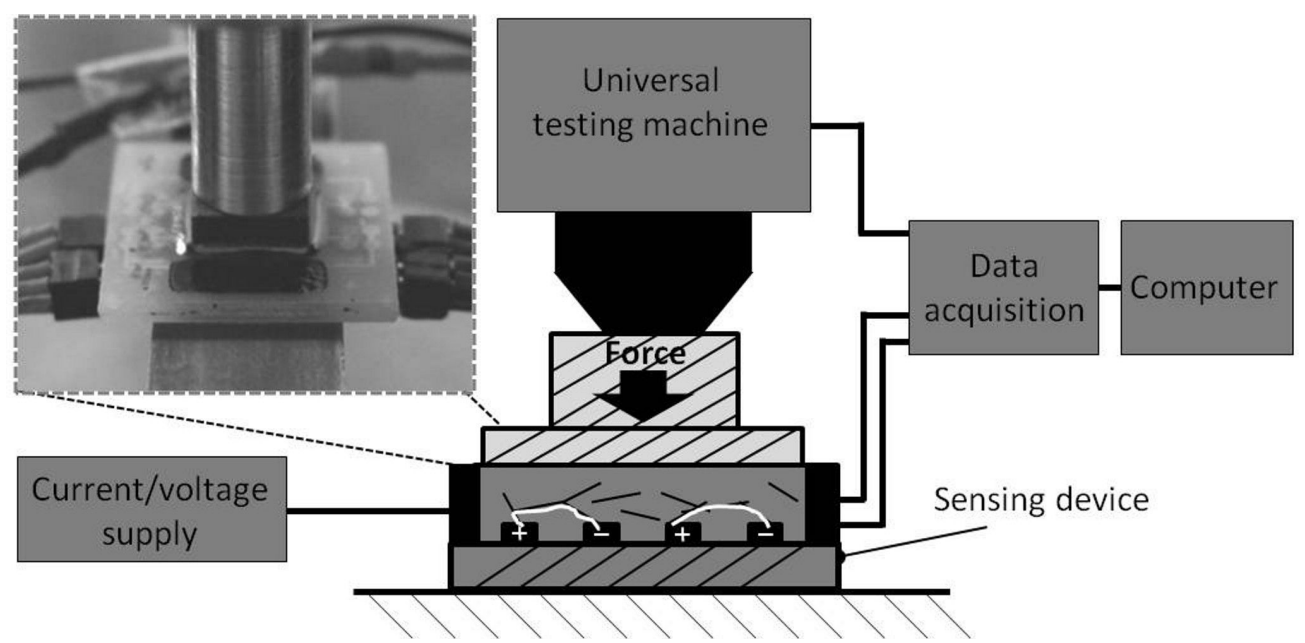

Figure 6. Force/pressure measurement setup.

\section{Results and Discussions}

A suitable viscosity of the composite is very important for a homogenous layer deposition. Therefore, the viscosity of the MWCNT-epoxy composite is measured in this section. In order to investigate the influence of the filler content, the sensitivity and the signal-to-noise ratio from different MWCNT concentrations are characterized. For a sensor application, the temperature influences is not negligible. A comparison between the resistance change due to the pressure and the cross-sensitivity due to the temperature can give an assessment of the resolution or the working temperature. To compensate for the temperature influence, a bridge circuit was used. Finally, the temperature sensitivity of one element and the temperature sensitivity of the bridge circuit are compared.

\subsection{Viscosities of MWCNT-Epoxy Dispersion}

Bauhofer et al. show a relationship between the rheology and the conductivity of an MWCNT-epoxy [44]. The viscosity strongly increases after the electrical percolation threshold is reached. Furthermore, the suitable rheology is important to get homogeneous layers by the blade coating process. On that score, the rheology is measured with a rheometer "Physica MCR 301, Anton Paar". Figure 7 shows the viscosity and the shear rate of the unfilled epoxy and $2 \mathrm{wt} \%$-filled dispersion of different mixing states.

The unfilled epoxy has a viscosity of $1.3 \mathrm{~Pa} \cdot \mathrm{s}$ and shows the behavior of a Newtonian fluid, where the viscosity is independent of the shear rate. On the other hand, $2 \mathrm{wt} \%$-filled epoxy shows a shear-thinning behavior, and the viscosity is multiply increased. Additionally, a strong increase of viscosity was obtained after the three-roll mixing process. The viscosity of a $2 \mathrm{wt} \%$ magnet-stirred dispersion is $122 \mathrm{~Pa} \cdot \mathrm{s}$; however the viscosity of the same filler content fabricated by the three-roll mixer is $794 \mathrm{~Pa} \cdot \mathrm{s}$ (at a shear rate of $1(1 / \mathrm{s})$ ). The high viscosity can be explained by a more effective unbundling of MWCNTs through the three-roll mixer. Another possible reason is the alignment of MWCNTs caused 
by the mixing process [49]. To compare the dispersion efficiency, samples with different mixing methods are fabricated by blade coating (Figure 5a). The samples with $2 \mathrm{wt} \%$ fabricated by a magnetic stirrer have an average resistance of $3.64 \mathrm{k} \Omega$ (at $20^{\circ} \mathrm{C}$ ). Samples fabricated by the additional mixing step (three-roll mixer) have an average value of $3.1 \mathrm{k} \Omega\left(\right.$ at $20^{\circ} \mathrm{C}$ ). The nominal resistance after the three-roll mixing process is decreased by $15 \%$. This result leads to the conclusion that the MWCNTs are more effective when unbundled by the three-roll mixer.

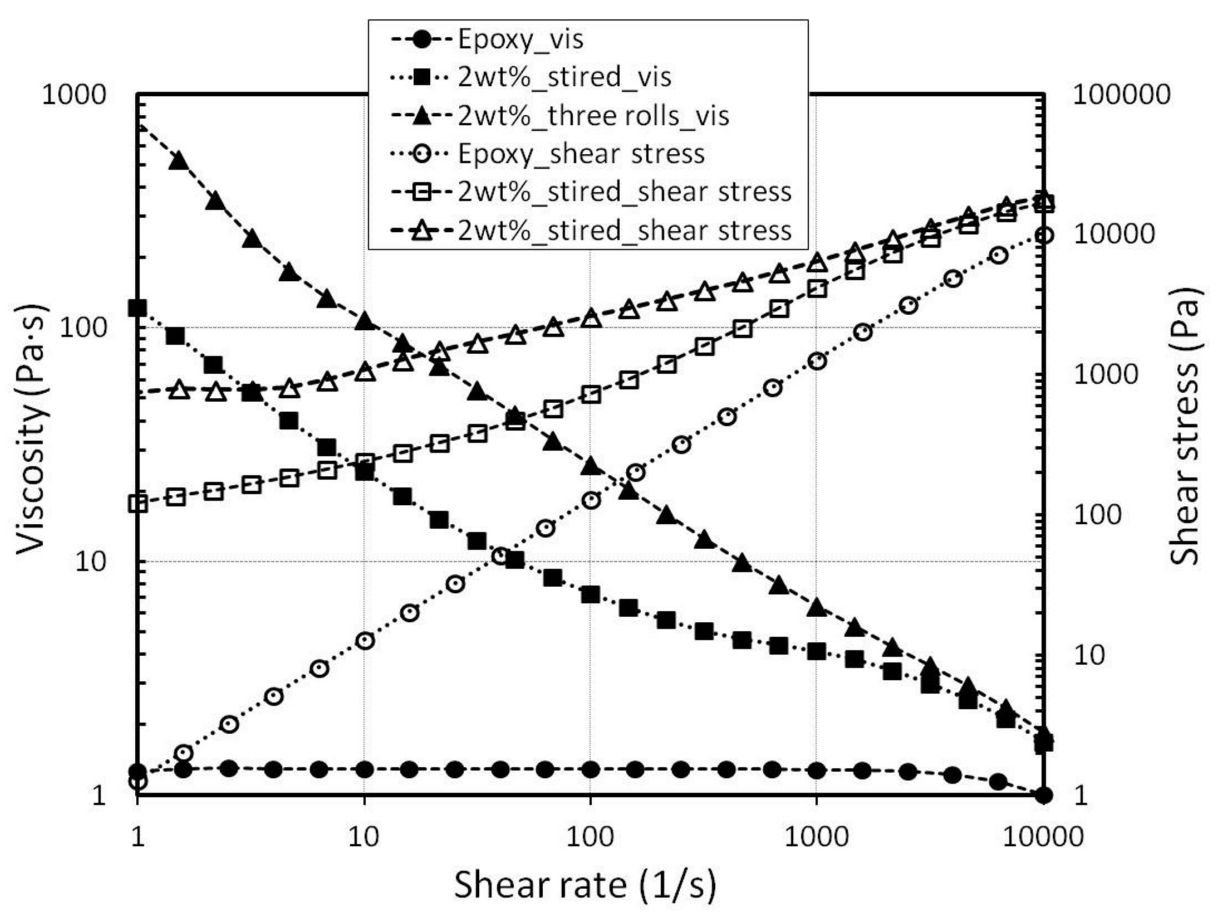

Figure 7. Viscosity of the dispersions at different mixing states.

\subsection{Resistance Behavior under Force/Pressure Loads}

In order to investigate the sensitivity depending on the filler content, only the resistance of a single element is measured. By applying a constant current of $15 \mu \mathrm{A}$, the voltage drop is measured, and the resistance is calculated by Ohm's law. Due to the clearance in the measurement setup, an initial load is necessary to press every component together. A stable electrical response is measured after an initial load between 50 and $150 \mathrm{~N}$ has been applied. The resistance decreases when the force is applied. Thus, this indicates that the establishment of electrical paths is dominating. For better comparisons, the absolute resistance changes (Abs $\Delta \mathrm{R}$ ) were calculated. The absolute resistance change at different filler contents is shown in Figure 8.

All curves show a non-linear behavior between force and resistance changes. Samples with lower filler content have higher sensitivity. This result corresponds with the experimental result of Yin et al. on the bending beam [43] and the numerical modeling result of Hu et al. [48]. The resistance change can be explained by the percolation theory [50] and the tunneling effect [48]. In a CNT network, the total resistance change is induced by the change of the number of the contact resistances and the tunnel resistances. At lower filler content, both of these resistance components are more marked [5]. For that reason, lower filler content has a higher sensitivity. 


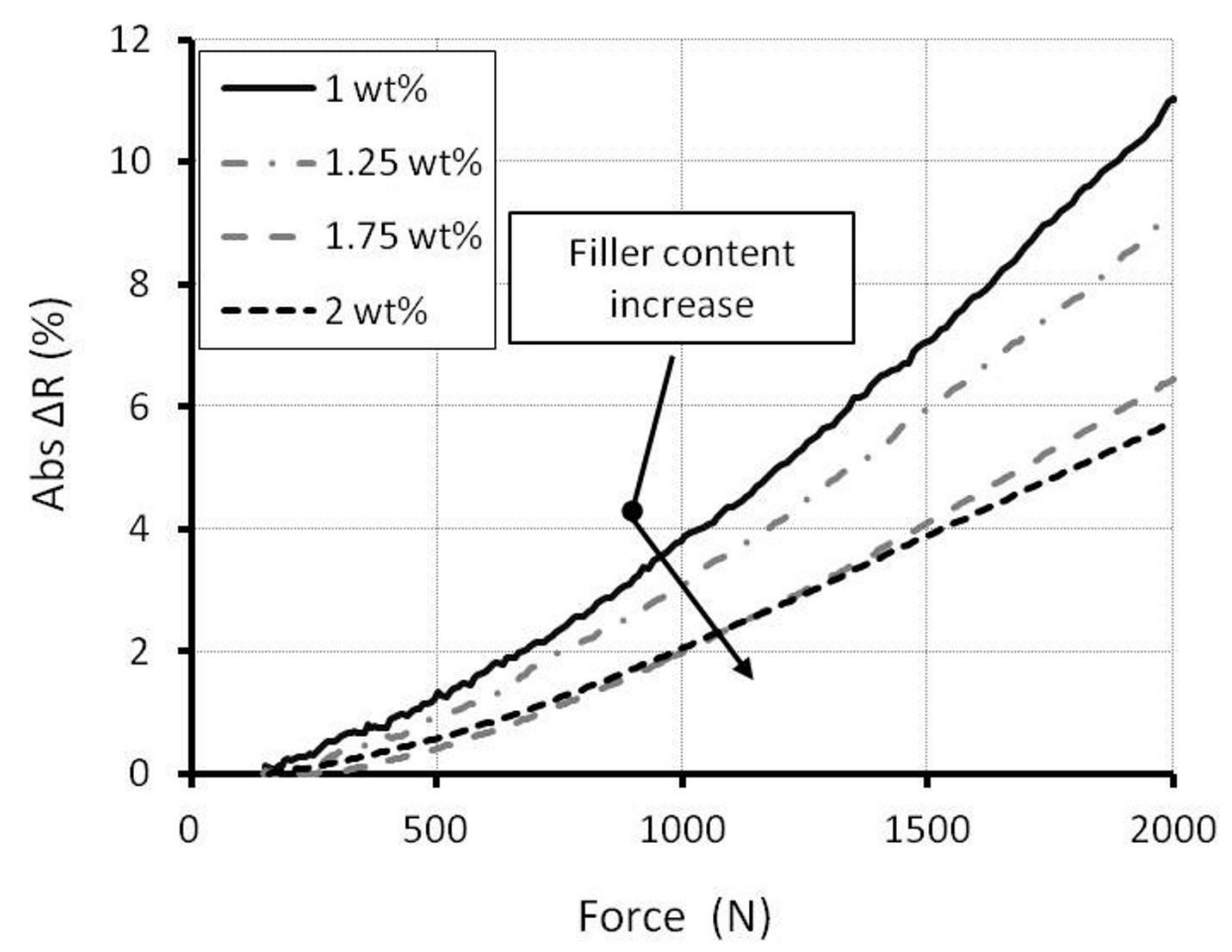

Figure 8. Absolute resistance change from different filler contents.

To explore the repeatability of the electrical signal, an alternating force from $150 \mathrm{~N}$ up to $2 \mathrm{kN}$ was applied to the sample. With a velocity of $0.1 \mathrm{~mm} / \mathrm{min}$, the electrical signal of five cycles was measured. The absolute resistance change of a sample with $2 \mathrm{wt} \%$ is depicted in Figure 9.

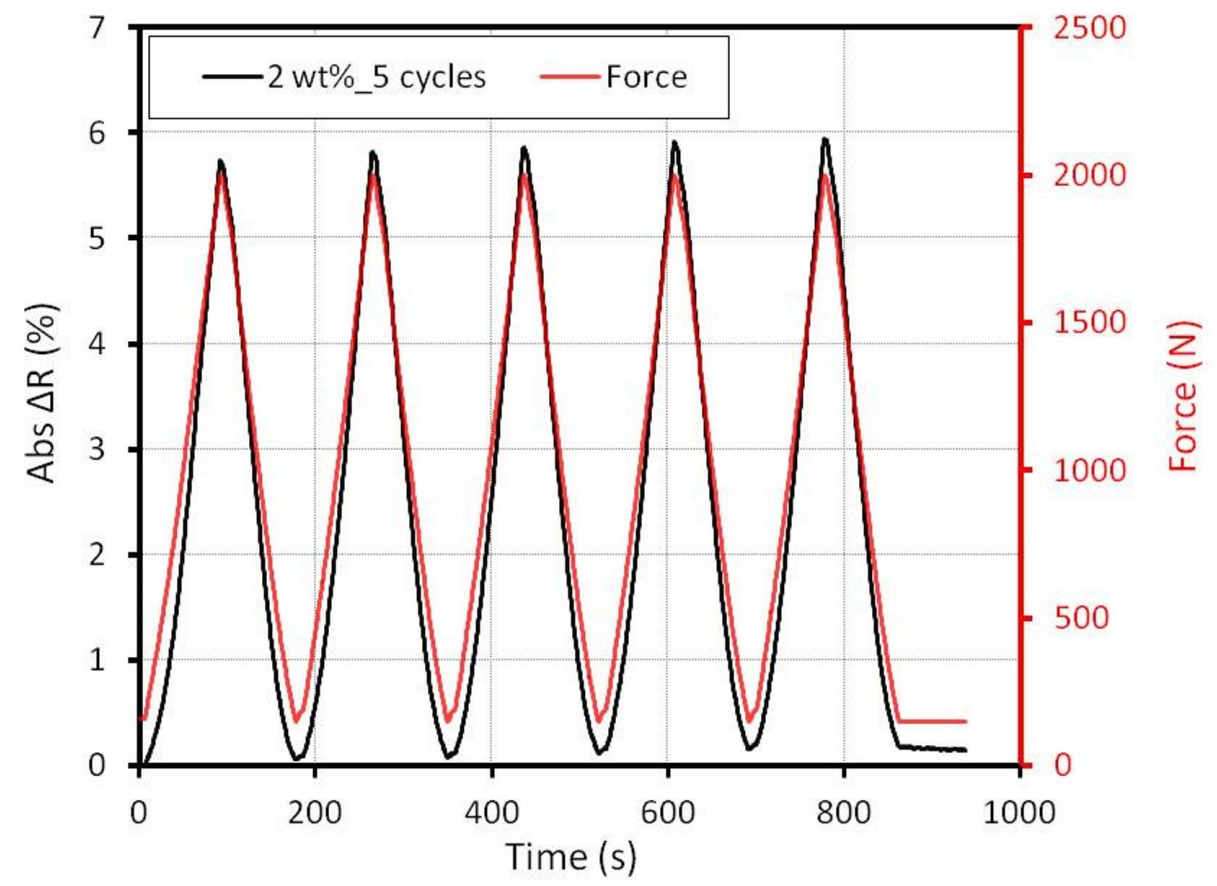

Figure 9. Absolute resistance change at five loading cycles (sample with $2 \mathrm{wt} \%$ ).

A small drift was obtained. Especially between the first cycles and the second cycle, there is a distinct difference on the reversal point. Nonetheless, the electrical response shows a reproducible characteristic 
in the following cycles. Before and after the measurement, the resistance of the sample was measured. The current-voltage (I-V) curves show no identifiable difference. Hence, we conclude that the stability of the MWCNT-epoxy is given up to a force of $2 \mathrm{kN}$ (pressure $20 \mathrm{MPa}$ ). There is no delay in the electrical response obtained. In one second, two measurements are taken $(2 \mathrm{~Hz})$. For that reason, a response time under $0.5 \mathrm{~s}$ can be expected.

Compared to the results from Yin et al. with MWCNT-epoxy [43] and Mohiuddin et al. with MWCNTs in polyether ether ketone (PEEK) [29], this performance shows a better reproducibility. The reproducibility in this study is comparable with the result of Kang et al., who used a SWCNT/polyimide composite [27] in pressure measurement. In contrast to Kang's report, less expensive MWCNTs were used in this work, and the sensitivity is higher. Furthermore, the applied pressure on the composite is up to $20 \mathrm{MPa}$, whereby the maximum pressure in the work of Kang et al. is $5 \mathrm{MPa}$.

In the next step, the four elements are collected into a Wheatstone bridge (sensor structure). Only the two elements in the middle are pressed by the testing machine. The measurement was started by an initial load of $50 \mathrm{~N}$. To investigated the stability of the electrical response, the forces are increased in $50-\mathrm{N}(0.5 \mathrm{MPa})$ steps. In each step, the force remained constant for two minutes. For a half bridge, the resistance change was calculated by Equation (1). The absolute resistance changes for different filler content by the stepped loading are depicted in Figure 10.

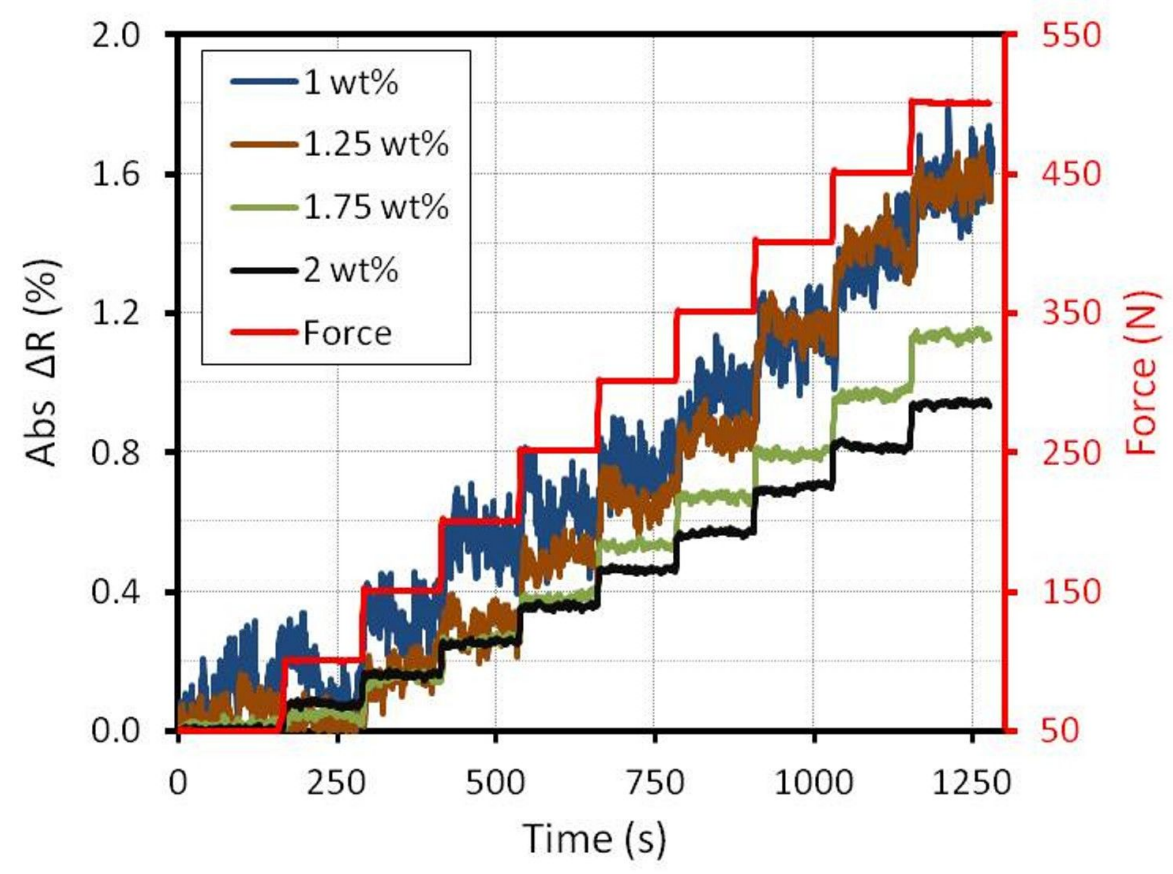

Figure 10. Stability of the signals by stepped loading in a half bridge circuit.

The signal of the $1.75 \mathrm{wt} \%$ and $2 \mathrm{wt} \%$ samples follow the loading. However, the signal of the $1 \mathrm{wt} \%$ sample could not follow the stepped loading due to the noise. Close to the electrical percolation threshold, the construction and destruction of electrical paths are unbalanced. In a small strain area, the resistance can take turns increasing or decreasing, although the total strain increases. Hence, the resistance change is unstable. This result corresponds with the theoretical and experimental result of $\mathrm{Hu}$ et al. for the stretching case [5]. The result of this work can show the noise behavior for lower filler content also for the compression case. 


\subsection{Temperature Influence on One Element}

As mentioned before, only one element was measured to investigate the temperature influence. The measurement begins at $80^{\circ} \mathrm{C}$. Before the measurement starts, the sample was warmed up for $6 \mathrm{~h}$ at $80^{\circ} \mathrm{C}$. The temperature decreased in $5^{\circ} \mathrm{C}$ steps and was maintained constant for $30 \mathrm{~min}$. After the desired temperature was reached, the resistance was measured ten times, and the average value was calculated. The reference resistances for this experiment are at $-20^{\circ} \mathrm{C}$. First of all, native MWCNT specimens were measured, as indicated with black lines in Figure 11. In order to avoid the humidity influence, specimens with $1.25 \mathrm{wt} \%$ and $2 \mathrm{wt} \%$ were covered with a 2-mm layer of polydimethylsiloxane (PDMS) afterwards. The resistances depending on the temperature of the covered specimens are indicated with red lines in Figure 11.

Lower filler content shows a higher sensitivity towards the temperature, and all samples have a positive temperature coefficient. This behavior is inverse to the negative temperature coefficient of MWCNTs, which are aligned and interconnected [51,52]. The negative temperature rises when the intrinsic conductivity of the MWCNTs is dominated. As can be seen in Figure 11, the sensitivities of PDMS-covered specimens are similar to the uncovered specimens. The covered specimen with a filler content of $1.25 \mathrm{wt} \%$ shows a lower sensitivity, with $50 \%$ at $80^{\circ} \mathrm{C}$, than the uncovered specimen, with $54 \%$ at $80^{\circ} \mathrm{C}$. On the other hand, the covered PDMS specimen with a filler content of $2 \mathrm{wt} \%$ shows a higher sensitivity, with $18 \%$ at $80^{\circ} \mathrm{C}$, than the uncovered specimen, with $16 \%$ at $80^{\circ} \mathrm{C}$. The tendency of the humidity influence is not identifiable in this experiment. However, it has been proven that the temperature influence is clearly the dominant effect.

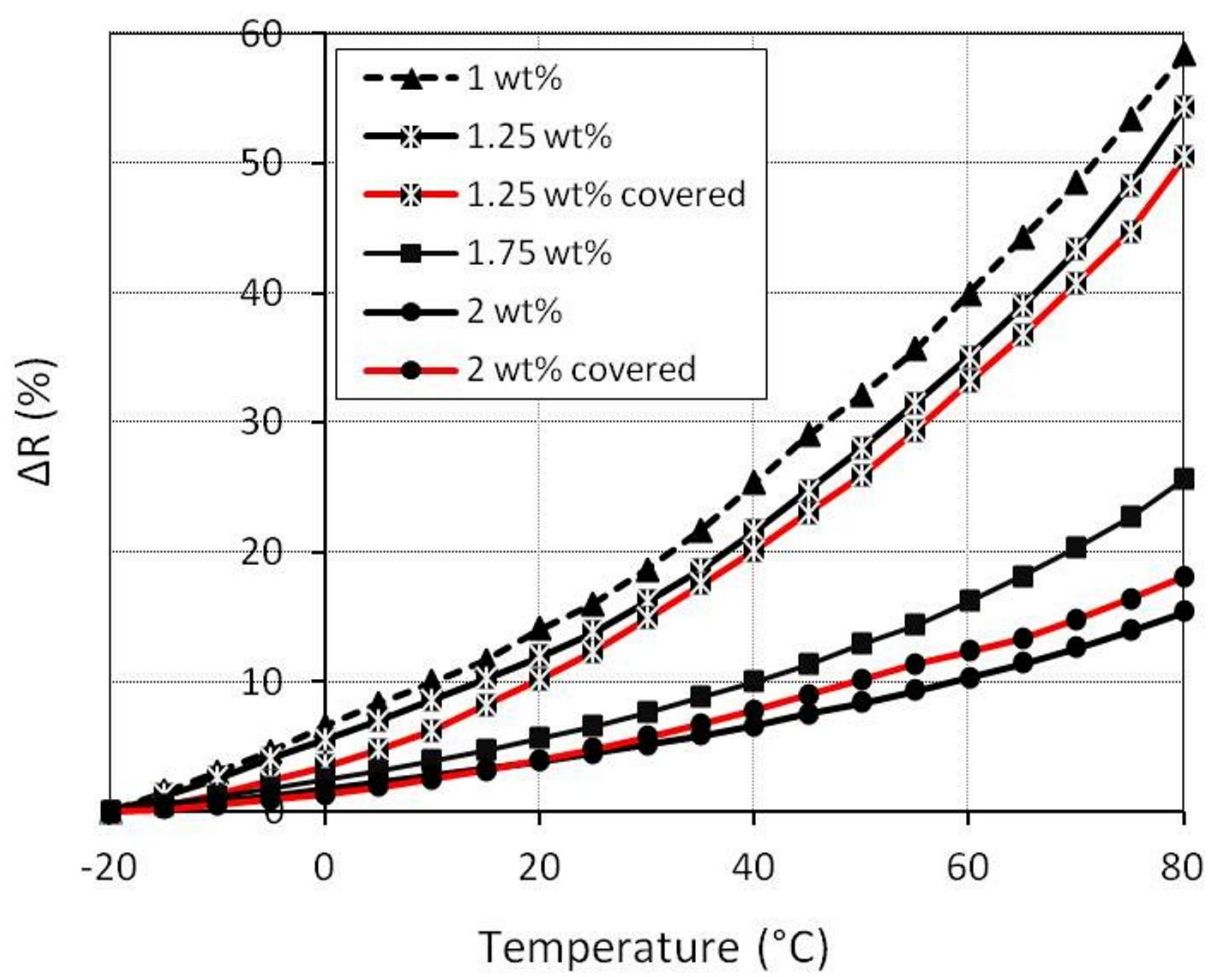

Figure 11. Temperature influence on the resistance. Black lines indicate native MWCNT specimens; red lines indicate PDMS-covered MWCNT specimens. 
In contrast to the interconnected MWCNTs, the contact resistance and the tunnel resistance are responsible for the resistance change in a composite. The volume expansion of the epoxy in a 3D composite is more dominant and is responsible for the positive temperature coefficient. When the volume expands, the distances between the MWCNTs increases. This causes a higher tunneling resistance or the contacts between the MWCNTs will be broken up. The result is a rise of resistance by increasing temperature. The measured results correspond to the investigation of Lasater et al., who have investigated the influence of the temperature on the resistance of CNT-epoxy composite [30].

In order to investigate the reproducibility of the temperature influence, the resistance dependence of the cycle from $-20^{\circ} \mathrm{C}$ up to $80^{\circ} \mathrm{C}$ is investigated in the next experiment. In the beginning, the temperature decreased from $80^{\circ} \mathrm{C}$ to $-20^{\circ} \mathrm{C}$. The value of the reference resistance at $-20^{\circ} \mathrm{C}$ is $3 \mathrm{k} \Omega$. Afterwards, the temperature increased again to $80^{\circ} \mathrm{C}$. As can be observed in Figure 12, the resistance change of the specimen with $2 \mathrm{wt} \%$ before and after covering with PDMS shows a hysteresis.

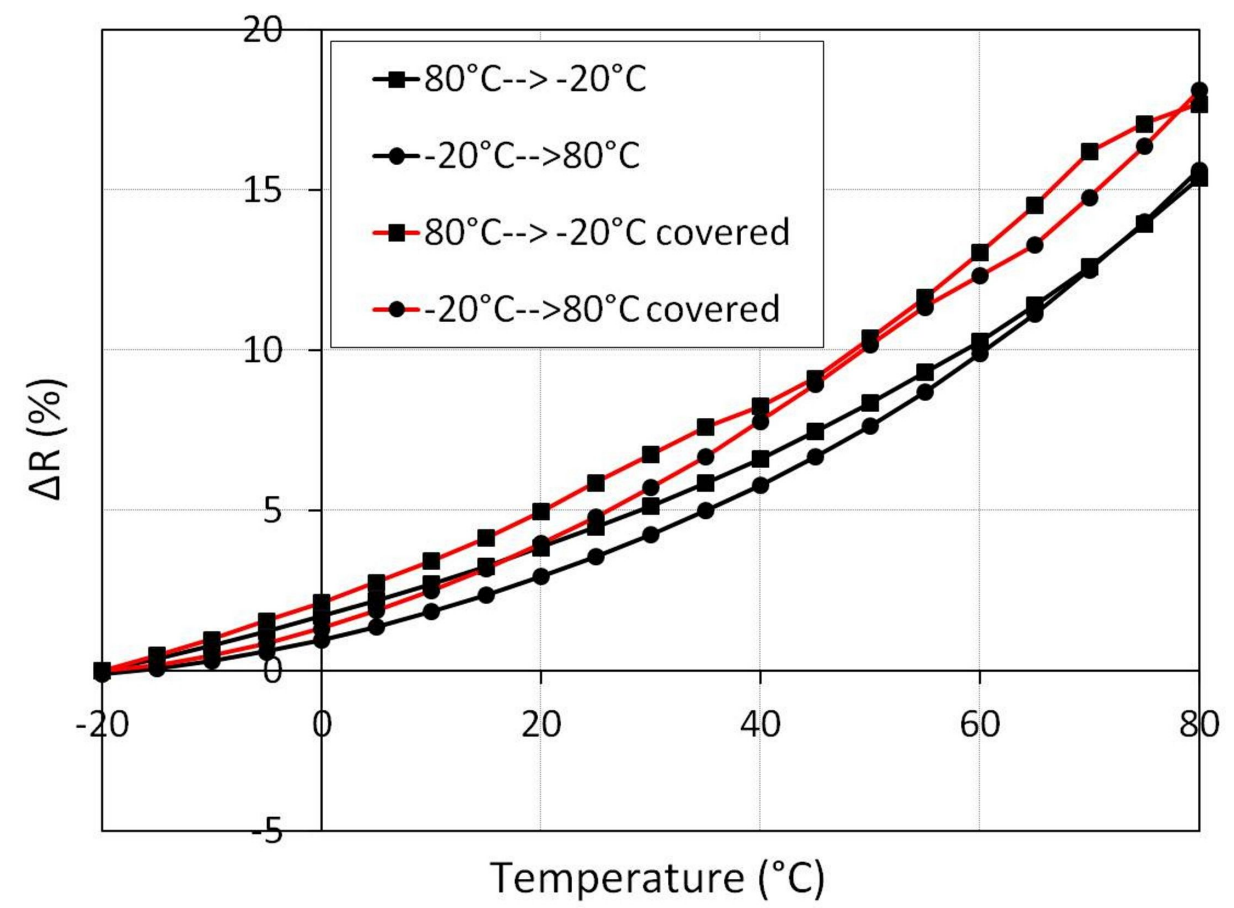

Figure 12. Resistance hysteresis in one temperature cycle (sample with $2 \mathrm{wt} \%$ ). Black lines indicate the native MWCNT specimen; red lines indicate the PDMS-covered MWCNT specimen.

The reason for the hysteresis could be the slow volume expansion/contraction processes of the epoxy. Nevertheless, the temperature dependency for one element is greater than the sensitivity to force and pressure. The whole resistance change for $2 \mathrm{kN}$ is about $6 \%$ (see Figure 9) for a specimen with $2 \mathrm{wt} \%$, while the resistance change caused by the temperature is $16 \%$ (Figure 12). This fact demonstrates that a pressure measurement using only one element is not recommended.

\subsection{Temperature Compensation}

Temperature compensation is necessary because of the high temperature dependence of the MWCNT composite. The conditions for effective temperature compensation with a Wheatstone bridge are that 
all elements have the same temperature coefficient and the nominal resistance values are similar. The detailed working mechanism for the temperature compensation are explained in Section 3.1. Owing to the same material composition, the four elements have the same temperature coefficient. Additionally, the fabrication processes lead to a resistance variation of $3.1 \%$. In this experiment, the same specimen with $2 \mathrm{wt} \%$, like in the previous experiments, was used. Although all four elements are responsible for the temperature compensation (full bridge), the resistance is calculated by the Equation (1) for the Wheatstone bridge. This allows a calculation of an equivalent measurement error, which is caused by the temperature. The temperature response calculated by the half bridge equation is depicted in Figure 13.

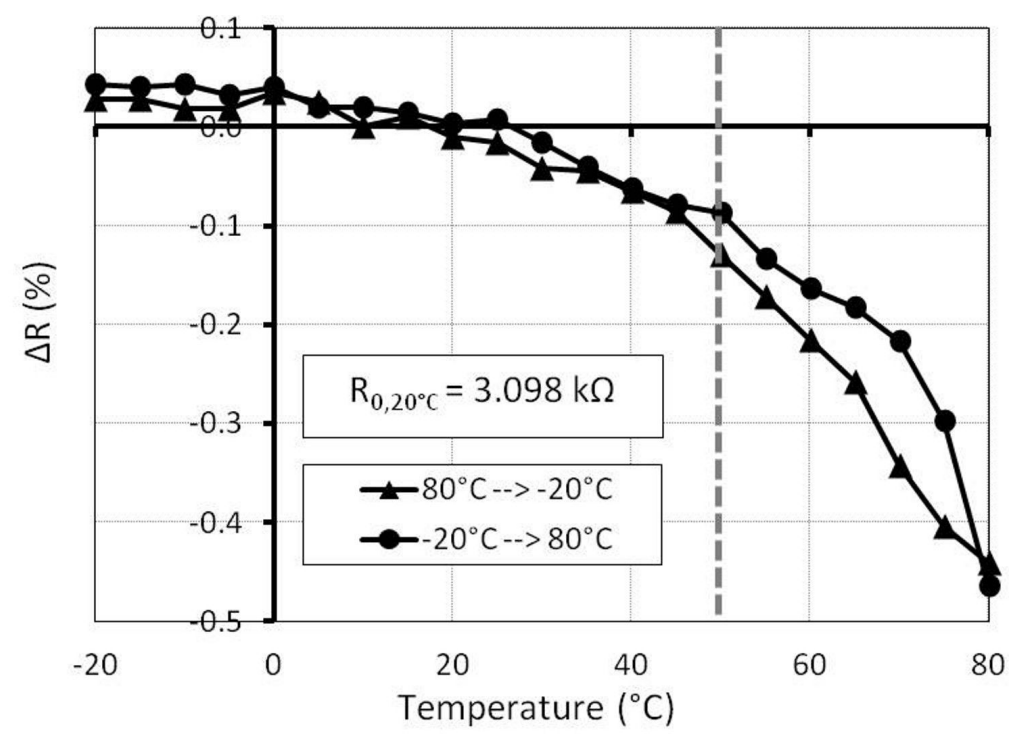

Figure 13. Temperature dependency of the Wheatstone bridge (sample with $2 \mathrm{wt} \%$ ).

In the whole temperature range from $-20^{\circ} \mathrm{C}-80^{\circ} \mathrm{C}$, the resistance change of the sensor structure is now only $1 \%$. This is 16-times smaller than the temperature sensitivity of one element (see Figure 12). The negative temperature dependence of the resistance in this specimen is not applicable to the other specimens. Depending on the resistance distribution of the single element, the temperature dependence can have a positive or negative gradient. In other words, the positive or negative gradient is randomly distributed. The higher the similarity (i.e., similar resistance value and temperature sensitivity) of the four elements, the higher is therefore the effectiveness of the temperature compensation.

When the working temperature is from $-20^{\circ} \mathrm{C}$ up to $80^{\circ} \mathrm{C}$, the measurement error will be $550 \mathrm{~N}$, which corresponds to $27.5 \%$ of the measurement range up to $2 \mathrm{kN}$. However, the working temperature range of most electronics is from $-20^{\circ} \mathrm{C}$ up to $50^{\circ} \mathrm{C}$. If this temperature range is considered, the resistance change in the bridge is only $0.3 \%$. In this case, a measurement error of $150 \mathrm{~N}$ can be expected, which corresponds to $7.5 \%$ of in the measurement range up to $2 \mathrm{kN}$.

\section{Conclusions}

In this work, the force/pressure sensing behaviors of MWCNT-epoxy composite up to $2 \mathrm{kN}$ (20 MPa) are investigated. For this aim, MWCNT-epoxy composite is dispersed first by a magnetic stirrer and second by a three-roll mixer. The resistance decrease after the three-roll mixing, leading to the conclusion 
that the MWCNTs are more efficiency dispersed. Hence, the viscosity is increased after the three-roll mixing process.

Additionally, this work reported the connection between pressure sensitivity, temperature dependency and electrical signal noise for a CNT composite. Pressure and temperature measurement show a higher sensitivity at lower MWCNT filler content. However, the electrical response of the lower filler content gives a noisy signal. For this reason, a compromise between these three aspects is needed for a sensor application. Samples with higher filler content (1.75 wt $\%, 2 \mathrm{wt} \%)$ show an improved total performance. At constant temperature, a force of at least $50 \mathrm{~N}(0.5 \mathrm{MPa})$ in a measurement range of $2 \mathrm{kN}(20 \mathrm{MPa})$ can be resolved with a sensor structure of $2 \mathrm{wt} \%$.

Temperature compensation was demonstrated with a Wheatstone bridge. Similar resistances are one condition for efficient temperature compensation. With the FEM modeling and the optimized fabrication processes, nominal resistances with a variation of $3.1 \%$ could be fabricated. By using a filler content of $2 \mathrm{wt} \%$, it has been shown that temperature dependence is decreased from $16 \%$ to $1 \%$. When the working temperature is defined from $-20^{\circ} \mathrm{C}-50{ }^{\circ} \mathrm{C}$, the temperature influence leads to a measurement error of $150 \mathrm{~N}(1.5 \mathrm{MPa})$.

\section{Acknowledgments}

The authors acknowledge the team of the Professorship of Conveyorson on the Technische Universität Chemnitz, especially Roland Liebold, Tino Grunert, Rocco Sickel and Ulrike Schneevoigt for the great support during the pressure measurements. Furthermore, we thank Steffen Schulze for the HRTEM analysis. Finally, we thank the organization "Bundesministerium für Wirtschaft und Energie”, especially the program Zentrales Innovationsprogramm Mittelstand (ZIM) (Grant Number KF 2837603WO2) for the financial funding.

\section{Author Contributions}

Nghia Trong Dinh: device design, sample manufacturing, experiment, data analysis, paper writing. Olfa Kanoun: project management, paper writing.

\section{Conflicts of Interest}

The authors declare no conflict of interest.

\section{References}

1. Germanton, D.; Cappiello, M.; Tasker, R.; Petrucelli, S. Electrical Weighing Scale. U.S. Patent 5,886,302, 23 March 1999.

2. Arshak, K.; McDonagh, D.; Durcan, M. Development of new capacitive strain sensors based on thick film polymer and cermet technologies. Sens. Actuators A Phys. 2000, 79, 102-114.

3. Jahn, S.; Blaudeck, T.; Baumann, R.; Jakob, A.; Ecorchard, P.; Rueffer, T.; Lang, H.; Schmidt, P. Inkjet printing of conductive silver patterns by using the first aqueous particle-free MOD ink without additional stabilizing ligands. Chem. Mater. 2010, 22, 3067-3071. 
4. Wang, C.; Hsieh, J.; Li, C. Electrical and piezoresistive properties of TaN-Cu nanocomposite thin films. Thin Solid Films 2004, 469-470, 455-459.

5. Hu, N.; Karube, Y.; Yan, C.; Masuda, Z.; Fukunaga, H. Tunneling effect in a polymer/carbon nanotube nanocomposite strain sensor. Acta Mater. 2008, 56, 2929-2936.

6. Jung, Y.J.; Kar, S.; Talapatra, S.; Soldano, C.; Viswanathan, G.; Li, X.; Yao, Z.; Ou, F.S.; Avadhanula, A.; Vajtai, R.; et al. Aligned Carbon Nanotube-Polymer Hybrid Architectures for Diverse Flexible Electronic Applications. Nano Lett. 2006, 6, 413-418.

7. Chang, F.Y.; Wang, R.H.; Yang, H.; Lin, Y.H.; Chen, T.M.; Huang, S.J. Flexible strain sensors fabricated with carbon nano-tube and carbon nano-fiber composite thin films. Thin Solid Films 2010, 518, 7343-7347.

8. Sepulveda, A.; Fachin, F.; de Villoria, R.G.; Wardle, B.; Viana, J.; Pontes, A.; Rocha, L. Nanocomposite Flexible Pressure Sensor for Biomedical Applications. Procedia Eng. 2011, 25, 140-143.

9. Saito, R.; Fujita, M.; Dresselhaus, G.; Dresselhaus, M. Electronic structure of chiral graphene tubules. Appl. Phys. Lett. 1992, 60, 2204-2206.

10. Kataura, H.; Kumazawa, Y.; Maniwa, Y.; Umezu, I.; Suzuki, S.; Ohtsuka, Y.; Achiba, Y. Optical properties of single-wall carbon nanotubes. Synth. Met. 1999, 103, 2555-2558.

11. Ebbesen, T.; Lezec, H.; Hiura, H.; Bennett, J.; Ghaemi, H.; Thio, T. Electrical conductivity of individual carbon nanotubes. Nature 1996, 382, 54-56.

12. Kim, P.; Shi, L.; Majumdar, A.; McEuen, P.C. Thermal transport measurements of individual multiwalled nanotubes. Phys. Rev. Lett. 2001, 87, 2155021-2155024.

13. Avouris, P. Molecular Electronics with Carbon Nanotubes. Acc. Chem. Res. 2002, 35, 1026-1034.

14. Cao, J.; Wang, Q.; Dai, H. Electromechanical properties of metallic, quasimetallic, and semiconducting carbon nanotubes under stretching. Phys. Rev. Lett. 2003, 90, 157601/1-157601/4.

15. Jang, H.S.; Lee, Y.H.; Na, H.J.; Nahm, S. Variation in electrical resistance versus strain of an individual multiwalled carbon nanotube. J. Appl. Phys. 2008, 104, doi:10.1063/1.3032905.

16. Zhao, J.; Dai, K.; Liu, C.; Zheng, G.; Wang, B.; Liu, C.; Chen, J.; Shen, C. A comparison between strain sensing behaviors of carbon black/polypropylene and carbon nanotubes/polypropylene electrically conductive composites. Compos. Part A 2013, 48, 129-136.

17. Watson, K.A.; Ghose, S.; Delozier, D.M.; Smith, J.G., Jr.; Connell, J.W. Transparent, flexible, conductive carbon nanotube coatings for electrostatic charge mitigation. Polymer 2005, 46, 2076-2085.

18. Wang, Z.; Liang, Z.; Wang, B.; Zhang, C.; Kramer, L. Processing and property investigation of single-walled carbon nanotube (SWNT) buckypaper/epoxy resin matrix nanocomposites. Compos. Part A 2004, 35, 1225-1232.

19. Schmidt, R.H.; Kinloch, I.A.; Burgess, A.N.; Windle, A.H. The Effect of Aggregation on the Electrical Conductivity of Spin-Coated Polymer/Carbon Nanotube Composite Films. Langmuir 2007, 23, 5707-5712.

20. Loh, K.J.; Kim, J.; Lynch, J.P.; Kam, N.W.S.; Kotov, N.A. Multifunctional layer-by-layer carbon nanotube-polyelectrolyte thin films for strain and corrosion sensing. Smart Mater. Struct. 2007, $16,429-438$. 
21. Kordas, K.; Mustonen, T.; Toth, G.; Jantunen, H.; Lajunen, M.; Soldano, C.; Talapatra, S.; Kar, S.; Vajtai, R.; Ajayan, P. Inkjet printing of electrically conductive patterns of carbon nanotubes. Small 2006, 2, 1021-1025.

22. Sanchez, M.; Rincon, M. Sensor response of sol-gel multiwalled carbon nanotubes- $\mathrm{TiO}_{2}$ composites deposited by screen-printing and dip-coating techniques. Sens. Actuators B Chem. 2009, 140, 17-23.

23. Wang, L.; Ma, F.; Shi, Q.; Liu, H.; Wang, X. Study on compressive resistance creep and recovery of flexible pressure sensitive material based on carbon black filled silicone rubber composite. Sens. Actuators A Phys. 2011, 165, 207-215.

24. Wang, L.; Wang, X.; Li, Y. Relation between repeated uniaxial compressive pressure and electrical resistance of carbon nanotube filled silicone rubber composite. Compos. Part A 2012, 43, 268-274.

25. Gerlach, C.; Krumm, D.; Illing, M.; Lange, J.; Kanoun, O.; Odenwald, S.; Hubler, A. Printed MWCNT-PDMS-Composite Pressure Sensor System for Plantar Pressure Monitoring in Ulcer Prevention. IEEE Sens. J. 2015, doi:10.1109/JSEN.2015.2392084.

26. Kanoun, O.; Mueller, C.; Benchirouf, A.; Sanli, A.; Dinh, T.N.; Al-Hamry, A.; Bu, L.; Gerlach, C.; Bouhamed, A. Flexible Carbon Nanotube Films for High Performance Strain Sensors. Sensors 2014, 14, 10042-10071.

27. Kang, J.H.; Park, C.; Scholl, J.A.; Brazin, A.H.; Holloway, N.M.; High, J.W.; Lowther, S.E.; Harrison, J.S. Piezoresistive characteristics of single wall carbon nanotube/polyimide nanocomposites. J. Polym. Sci. B Polym. Phys. 2009, 47, 994-1003.

28. Mohiuddin, M.; van Hoa, S. Electrical resistance of CNT-PEEK composites under compression at different temperatures. Nanoscale Res. Lett. 2011, 6, doi:10.1186/1556-276X-6-419.

29. Mohiuddin, M. Effect of Pressure and Temperature on Electrical Conductivity of CNT-PEEK Composites. Ph.D. Thesis, Concordia University, Montreal, QC, Canada, 2012.

30. Lasater, K.; Thostenson, E. In situ thermoresistive characterization of multifunctional composites of carbon nanotubes. Polymer 2012, 53, 5367-5374.

31. Mohiuddin, M.; Hoa, S. Temperature dependent electrical conductivity of CNT-PEEK composites. Compos. Sci. Technol. 2011, 72, 21-27.

32. Zhu, J.; Peng, H.; Rodriguez-Macias, F.; Margrave, J.L.; Khabashesku, V.N.; Imam, A.M.; Lozano, K.; Barrera, E.V. Reinforcing Epoxy Polymer Composites Through Covalent Integration of Functionalized Nanotubes. Adv. Funct. Mater. 2004, 14, 643-648.

33. Ma, P.C.; Kim, J.K.; Tang, B.Z. Effects of silane functionalization on the properties of carbon nanotube/epoxy nanocomposites. Compos. Sci. Technol. 2007, 67, 2965-2972.

34. McClory, C.; Poetschke, P.; McNally, T. Influence of Screw Speed on Electrical and Rheological Percolation of Melt-Mixed High-Impact Polystyrene/MWCNT Nanocomposites. Macromol. Mater. Eng. 2011, 296, 59-69.

35. Song, Y.S.; Youn, J.R. Influence of dispersion states of carbon nanotubes on physical properties of epoxy nanocomposites. Carbon 2005, 43, 1378-1385.

36. Shaffer, M.; Fan, X.; Windle, A. Dispersion and packing of carbon nanotubes. Carbon 1998, $36,1603-1612$. 
37. Frank, S.; Poncharal, P.; Wang, Z.; de Heer, W. Carbon nanotube quantum resistors. Science 1998, 280, 1744-1746.

38. Bachtold, A.; Strunk, C.; Salvetat, J.P.; Bonard, J.M.; Forro, L.; Nussbaumer, T.; Schoenenberger, C. Aharonov-Bohm oscillations in carbon nanotubes. Nature 1999, 397, 673-675.

39. Dutta, A. Electrical conductivity of single crystals of graphite. Phys. Rev. 1953, 90, 187-192.

40. Telling, R.; Ewels, C.; El-Barbary, A.; Heggie, M. Wigner defects bridge the graphite gap. Nat. Mater. 2003, 2, 333-337.

41. Agrawal, S.; Raghuveer, M.; Li, H.; Ramanath, G. Defect-induced electrical conductivity increase in individual multiwalled carbon nanotubes. Appl. Phys. Lett. 2007, 90, doi:10.1063/1.2737127.

42. Kordrostami, Z.; Sheikhi, M.; Mohammadzadegan, R. Modeling electronic properties of multiwall carbon nanotubes. Fuller. Nanotubes Carbon Nanostruct. 2008, 16, 66-77.

43. Yin, G.; Hu, N.; Karube, Y.; Liu, Y.; Li, Y.; Fukunaga, H. A carbon nanotube/polymer strain sensor with linear and anti-symmetric piezoresistivity. J. Compos. Mater. 2011, 45, 1315-1323.

44. Bauhofer, W.; Kovacs, J.Z. A review and analysis of electrical percolation in carbon nanotube polymer composites. Compos. Sci. Technol. 2009, 69, 1486-1498.

45. Wichmann, M.; Buschhorn, S.; Gehrmann, J.; Schulte, K. Piezoresistive response of epoxy composites with carbon nanoparticles under tensile load. Phys. Rev. B 2009, 80, doi:10.1103/ PhysRevB.80.245437.

46. Wichmann, M.H.G.; Buschhorn, S.T.; Boeger, L.; Adelung, R.; Schulte, K. Direction sensitive bending sensors based on multi-wall carbon nanotube/epoxy nanocomposites. Nanotechnology 2008, 19, doi:10.1088/0957-4484/19/47/475503.

47. Hu, N.; Masuda, Z.; Yamamoto, G.; Fukunaga, H.; Hashida, T.; Qiu, J. Effect of fabrication process on electrical properties of polymer/multi-wall carbon nanotube nanocomposites. Compos. Part A 2008, 39, 893-903.

48. Hu, N.; Karube, Y.; Arai, M.; Watanabe, T.; Yan, C.; Li, Y.; Liu, Y.; Fukunaga, H. Investigation on sensitivity of a polymer/carbon nanotube composite strain sensor. Carbon 2010, 48, 680-687.

49. Rahatekar, S.S.; Koziol, K.K.K.; Butler, S.A.; Elliott, J.A.; Shaffer, M.S.P.; Mackley, M.R.; Windle, A.H. Optical microstructure and viscosity enhancement for an epoxy resin matrix containing multiwall carbon nanotubes. J. Rheol. 2006, 50, 599-610.

50. Nan, C.W.; Shen, Y.; Ma, J. Physical properties of composites near percolation. Annu. Rev. Mater. Res. 2010, 40, 131-151.

51. Graugnard, E.; de Pablo, P.; Walsh, B.; Ghosh, A.; Datta, S.; Reifenberger, R. Temperature dependence of the conductance of multiwalled carbon nanotubes. Phys. Rev. B 2001, 64, 1254071-1254077.

52. Jakubinek, M.B.; White, M.A.; Li, G.; Jayasinghe, C.; Cho, W.; Schulz, M.J.; Shanov, V. Thermal and electrical conductivity of tall, vertically aligned carbon nanotube arrays. Carbon 2010, 48, 3947-3952.

(C) 2015 by the authors; licensee MDPI, Basel, Switzerland. This article is an open access article distributed under the terms and conditions of the Creative Commons Attribution license (http://creativecommons.org/licenses/by/4.0/). 